\title{
Um Debate Metodológico Sobre a Aceitação das Práticas dos Direitos Humanos em Finnis a Partir da Crítica de Beitz às Teorias da Lei Natural
}

\begin{abstract}
Ayrton Borges Machado
Mestrando em Direito pelo Programa de Pós-Graduação em Direito pela Universidade Federal do Pará (Ufpa). Bolsista (Capes). Graduado em Direito pela Universidade Federal do Pará. Integrante do Grupo de Pesquisa "Tradição da Lei Natural" (CNPq). Experiência na área de Direito, com ênfase em Filosofia do Direito. http://lattes.cnpq.br/5330704084462688. https://orcid.org/0000-0003-2828-4909. ayrtonmachado95@gmail.com

\section{Victor Sales Pinheiro}

Professor-adjunto da Universidade Federal do Pará (Ufpa) e do Centro Universitário do Pará (Cesupa), na Graduação e Pós-Graduação. Coordenador dos Grupos de Pesquisa (CNPq) "Tradição da Lei Natural" e "Razão pública, secularização e direitos humanos: casos, princípios e teorias políticas" e vice-coordenador do Grupo "AdmEthics - Ética, Virtudes e Dilemas Morais na Administração". Doutorado em Filosofia pela Uerj. Mestrado em Filosofia pela PUC-RIO. Graduação em Direito no Centro Universitário do Pará. Site de cursos, palestras, artigos e edições: www.dialetico.com. br. http://lattes.cnpq.br/0416222855469529. https://orcid.org/0000-0003-1908-9618. vvspinheiro@yahoo.com.br
\end{abstract}

O presente artigo visa a apresentar como a metodologia da lei natural em John Finnis fornece suporte para explicar a incorporação dos direitos humanos como práticas, sem prejudicar a função crítica que uma teoria do direito natural deve desempenhar em relação às instituições. A primeira parte do artigo expõe a metodologia e os pressupostos da lei natural relevantes para o tema, quais sejam, método do caso central, aceitação da normatividade das práticas e direitos ainda que desviantes, tendência descritiva e avaliativa contemporânea de incorporar práticas, e a distinção entre derivação por conclusão e determinatio. Na segunda parte expõe-se as críticas de Charles Beitz às teorias naturalistas, com o objetivo de apresentar os tópicos relevantes para o problema em questão. Por fim, aplica-se as considerações metodológicas feitas na primeira parte, de modo a mostrar como uma teoria da lei natural pode explicar a incorporação das práticas dos direito humanos, sobretudo quanto ao uso da analogia e caso central.

Palavras-chave: John Finnis. Metodologia. Lei natural. Caso central. Práticas.

\section{A METHODOLOGICAL DEBATE ON ACCEPTANCE OF HUMAN RIGHTS PRACTICES IN FINNIS} SINCE BEITZ'S CRITICISM TO NATURAL LAW THEORIES

ABSTRACT

This paper aims to present how John Finnis' methodology of natural law provides support for explaining the incorporation of human rights as practices without undermining the critical function that a theory of natural law must play in the face of institutions. The first part of the paper exposes the methodology and assumptions of natural law relevant to the theme, namely, the central case method, acceptance of the normativity of practices and rights, although deviant, contemporary descriptive and evaluative tendency to incorporate practices, and the distinction between derivation by conclusion and determinatio. In the second part, Charles Beitz's critiques of naturalistic theories are presented in order to present the topics relevant to the problem in question. Finally, we apply the methodological considerations made in the first part, in order to explain how a theory of natural law can explain the incorporation of human rights practices, especially regarding the use of analogy and central case.

Keywords: John Finnis. Methodology. Natural law. Central case. Practices.

SUMÁRIO

1 Introdução. 2 A metodologia da lei natural. 3 A crítica de Beitz: tópicos para um debate. 4 Aplicação dos pressupostos e métodos da lei natural aos direitos humanos. 5 Conclusão. 6 Referências.

Recebido em: 29/9/2019

Modificações solicitadas em: 16/12/2019

Aceito em: 7/4/2020 


\section{Humanos e \\ Democracia}

\section{INTRODUÇÃO}

A nova teoria da lei natural, como verifica-se em Finnis, é expressamente uma explicação não somente dos temas clássicos do direito natural, mas também uma tentativa de adaptá-los às novas circunstâncias e problemas. Ainda que se diga que esses novos problemas já estavam respondidos de uma determinada forma por teorias anteriores do direito natural, a atitude mais correta é reconhecer que eles são novos. A questão aqui tratada é exatamente um assunto deste tipo, ou seja, é um problema novo, trata-se dos direitos humanos. Finnis expressamente incorpora a linguagem dos direitos humanos, como se pode ver em Natural Law and Natural Rights (FINNIS, 2011c), quando ele explica o que são direitos no capítulo VIII - Direitos, ou na sua obra Aquinas (FINNIS, 1998), quando explica a dignidade e o sentido em direção aos direitos humanos no V - Towards Human Rights. Do mesmo modo, Finnis tem todo um volume de ensaios dedicados aos direitos humanos, o Human Rights and Common Good (FINNIS, 2011b); mas como a sua teoria pode explicar essa aceitação?

O presente trabalho tem, em grande parte, o caráter de ser metodológico, porque vai até as bases da teoria da lei natural finnisiana e nestas tenta encontrar possíveis respostas para o problema da incorporação das práticas emergentes dos direitos humanos. O problema do artigo, portanto, é: "Como as bases metodológicas da teoria finnisiana sobre direitos humanos, tendo fundamento na lei natural, podem justificar a incorporação das práticas emergentes dos direitos humanos?" Para tanto, utiliza-se, como ponto de vista problematizador, a visão de Beitz (2009), autor que critica a visão naturalista dos direitos humanos, na qual, de alguma forma, Finnis se insere. O objetivo do artigo não é propriamente responder a Beitz por meio da teoria de Finnis. No presente artigo, Beitz é utilizado como autor que apresenta um elenco de questionamentos para estimular as respostas que a teoria de Finnis pode oferecer. Desse modo, tem a utilidade mais de apresentar um elenco ou tópicos para a análise do que de ser uma crítica direta a Finnis.

Primeiramente realiza-se uma explicação da metodologia da lei natural quanto ao caso central, o uso da analogia, a moderação na desobediência de direitos e pressuposto de tomar as instituições e práticas como pontos de partida, principalmente a partir das obras Aquinas (1998), Natural Law and Natural Rights (2011c) e Direito natural em Tomás de Aquino (2007). Em seguida, expõe-se a crítica de Beitz a partir de Idea of Human Rights (2009) e From practice to theory (2013) acerca das teorias naturalistas dos direitos humanos e seus entraves às práticas, a fim de pontuar os desafios principais a que Finnis teria de responder (CORREAS, 2015). Por fim, realiza-se uma exposição de como os aspectos metodológicos da nova teoria da lei natural aplicam-se aos direitos humanos, e a forma que ela usa para explicar como essa teoria alberga a noção de práticas, e em que medida ela própria limita sua aceitação.

\section{A METODOLOGIA DA LEI NATURAL}

Os pontos metodológicos são relevantes para a presente exposição, porque se trata de perscrutar o que está na fronteira entre ser ou não direitos humanos: se por um lado é cabível aderir a uma descrição acrítica das práticas dos direitos humanos, adotando uma metodolo- 
gia estritamente descritivista, ou se é possível, ainda que aceitando as práticas, adotar uma postura crítica quando necessário. Em ambos os casos, o problema de fundo é como proceder nessa identificação do limite do que é direito, e, estritamente, o que é direito humano.

Na sua obra Direito Natural, Ética e Hermenêutica, Engelmann (2007) percebe bem essa importância metodológica em Finnis. Engelmann (2007, p. 144) sustenta que Finnis "está pretendendo catalogar os princípios da lei natural como uma preliminar ética ou como uma fórmula ética para uma teoria social". Logo, uma das principais transformações feitas por Finnis nas teorias do direito natural é metodológica, isto é, reformular a orientação para a avaliação dos casos e para a normatividade.

Alguns pontos da metodologia finnisiana são imprescindíveis a esse propósito, e esta exposição propõe-se a comentá-las como preparação para responder o problema. Os temas metodológicos relevantes são: 1 . O método do caso central; 2 . Aceitação da normatividade de formas defectivas de direito 3. Derivação por conclusão e por determinação; 4 . Tendência finnisiana de aceitar as práticas dadas.

Se se quer pensar como é possível identificar quando é legítimo falar de direitos humanos e quando é impróprio assim chamá-lo, então a explicação do caso central se faz necessária. O caso central é o caso exemplar para a avaliação das demais situações que dele se aproximam de modo mais perfeito ou imperfeito. Constitui-se, portanto, como um critério descritivo e avaliativo da prática (CROWE, 2016).

É preciso distinguir caso central de outro método chamado indutivista. O caso central não é um colecionamento das características comuns a abarcar todos os estados de coisas (FINNIS, 2011c, p. 9-10), ou um critério gerado por um método estatístico de frequência e ocorrência (FINNIS, 2011c, p. 10). O interessante de se estabelecer um caso central não é a busca por abarcar o maior número de situações, e, sim, o interesse está em afastar ou aproximar, em graus maiores ou menores, os casos que servem e os que não servem para se promover com razoabilidade uma determinada prática, a exemplo da instituição chamada direitos humanos, que se comenta ao final do artigo, segundo a teoria da lei natura em Finnis.

Nessa análise dialética de aproximação e distanciamento, identifica-se o significado focal, que é o princípio que estabelece o porquê de um caso ser central e outros não, à medida que aqueles que se distanciam deste sentido, sendo casos periféricos, adotam significados secundários (FINNIS, 2011c, p. 11-12). O desafio que se interpõe à teoria é explicar como esses significados focais são estipulados, e tal tarefa cumpre-se pela identificação do ponto de vista prático, em que prático significa aquilo que é adequado para o propósito da decisão da ação (FINNIS, 2011c, p. 12). Toda a teoria de Finnis é, de alguma forma, uma fundamentação para a orientação da razoabilidade das ações, das práticas sociais e, em particular, do ponto de vista legal. O método do caso central, que pressupõe um sentido focal, é relevante para explicar como Finnis pode ser, ao mesmo tempo, crítico e incorporador dos direitos humanos enquanto prática dada.

A reflexão sobre o caso central e o significado focal nos leva a um problema específico: o da aceitabilidade da normatividade de casos periféricos. Em primeiro lugar, é preciso entender que, do ponto de vista contingencial, nenhum caso particular jamais pode instanciar perfeitamente o caso central, não porque seja impossível a aproximação dos elementos entre um e outro, mas porque logicamente não é possível, pois existe uma limitação de categorias 


\section{Democracia}

Humanos e

que os separa. A tarefa da metodologia do caso central em Finnis, todavia, é propriamente a de contribuir para que a pesquisa social reflita em termos de aproximação. Desse modo, todos os casos particulares são defectivos? De certa maneira sim; em sentido próprio é o caso central que é normativo, mas os modelos que dele se aproximem em grau máximo também podem ser normativos.

O ponto mais importante acerca da aceitabilidade da normatividade de casos "periféricos" para o debate que se realiza é quando o caso central é relativo ao direito, isto é, o ponto de vista legal (AIYAR, 2000). Afirma Finnis: "Se existe um ponto de vista no qual uma obrigação legal é tratada, pelo menos presumivelmente, como uma obrigação moral, (...) então tal ponto de vista constituirá o caso central do ponto de vista legal" (2011c, p. 14-15. Tradução nossa). ${ }^{1}$ A obrigação moral presumível é a sua razoabilidade, isto é, que o direito considere o fundamento de que ele promove alguma razão última para a ação, ou pelo menos não a impeça. Esta razão, todavia, pode ser apenas presumível, e isto significa que: i) se não for flagrantemente oposta aos bens mais básicos, o comando autoritativo para a ação (ex.: um tratado de direitos) ainda gera obrigação; e ii) gera obrigação presumível desde que a desobediência seja mais danosa do que os danos que adviriam obediência, ainda que tal forma de comando da autoridade não seja perfeitamente razoável, apenas o suficiente para ser presumível.

A teoria da lei natural não é dogmática ou peremptória em pensar que somente é normativo aquilo que estritamente esteja de acordo com bens básicos (MURPHY, 2005). Ela, tendo por base a analogia, e entende que os sistemas jurídicos particulares não são puros. Como Kaufmann (2004) sustenta, direitos humanos muitos gerais encontram verdadeira dificuldade quando de sua especificação, e é neste momento que se percebe que a analogia é relevante, para se poder medir o grau de aproximação do direito natural que essas especificações dos direitos humanos possuem (KAUFMANN, 2004, p. 286). Os sistemas jurídicos particulares estão sempre nessa zona de aceitabilidade, que está entre o caso central, como modelo simpliciter de realizar os propósitos dos bens básicos, e os modelos absolutamente rejeitáveis, aqueles para os quais a questão não é serem imperfeitos na promoção dos bens básicos, mas, sim, que são frontalmente opostos a tais tipos de bens. Estando nessa zona de aceitabilidade, então o direito em questão ainda sustenta sua normatividade presuntiva. Isto se dá, além das razões apresentadas, principalmente porque, enquanto sujeitos particulares, há uma limitação na capacidade de julgar e projetar consequências a ponto de rejeitar normas ou comandos que sustentem dúvidas de sua adequação na promoção dos bens básicos. Logo, apesar das dúvidas que um comando possa produzir, estes ainda podem conseguir gerar algum nível razoável de ordem.

A aceitabilidade dessas circunstâncias duvidosas conduz a outro ponto importante, a forma de derivação da lei natural para a forma de direitos: se esta se dá por conclusão ou por determinação (determinatio) (FINNIS, 1998, p. 266). Distinguir estes dois modos importa em evitar compreensões equivocadas, como aquelas que julgam erroneamente que a teoria da lei natural defende uma aplicação direta da lei natural, como se ignorasse os meios empíricos de realização; pelo contrário, a lei natural precisa da atividade criadora humana e de elemen-

"If there is a point of view in which legal obligation is treated as at least presumptively a moral obligation (...) then such a viewpoint will constitute the central case of the legal viewpoint" (FINNIS, 2011c, p. 14-15). 
tos culturais para dar forma à realização do propósito dos bens básicos. Essa derivação da lei natural, cuja inferência tem um grau de discricionariedade, isto é, em que o seu conteúdo é parcialmente determinado pela escolha humana, orientada pela razoabilidade, chama-se determinatio (FINNIS, 2007, p. 96-98). Por outro lado, denomina-se conclusão o tipo de derivação da lei natural, que implica uma lei cujo conteúdo é completamente inferido e delimitado pela lei natural, prescindindo da atividade criadora humana na construção de seu enunciado, bastando uma dedução direta para a sua inferência.

Por fim, é preciso destacar que Finnis, além de se vincular à filosofia tomista, está na tradição contemporânea da teoria do direito que o influencia em algumas tendências: a primeira é a de não ser crítico aos direito humanos e não o acusar de ser ideológico, atitude acusatória que tem sido tomada por outras escolhas da teoria do direito natural. A segunda tendência é a de tomar como base para a sua teoria as práticas contemporâneas do direito, como são os próprios direitos humanos, uma prática atual e que por ele é assumida. Isso se dá porque Finnis pretende construir uma teoria do direito (que também é uma teoria política) tal qual outros autores contemporâneos fazem, ou seja, partindo de práticas preexistentes (OLIVEIRA, 2002).

Este ponto é imprescindível para a presente investigação. Partir de práticas existentes é típico de uma filosofia que tem interesse em não ser dogmática a ponto de se fazer prescrita tão logo seus conceitos e esquemas não encontrem efeito no mundo prático. Além disso, é também uma atitude teórica de uma filosofia que não quer ser somente crítica, isto é, que pense somente como os fenômenos deveriam ser ou que tente desmascarar formas jurídicas que escondem tendências ideológicas espúrias. A teoria da lei natural tomista, renovada por Finnis, tem interesse em, além de ser crítica, também ser útil para explicar as práticas atuais sem as acusar de ilegítimas (VALLEJO, 2013).

O ônus dessa adaptação da teoria clássica para essas novas tendências é o de não implodir as categorias fundamentais da teoria da lei natural e se manter coerente com a tradição de que tanto se aprecia pela sua unidade e completude (SCANDROGLIO, 2012). A afirmação da unidade, contudo, não pode ser dogmática, isto é, não pode apenas firmar doutrinariamente um sistema de conceitos intocável. O próprio método do caso central é um método pelo qual se busca ajustar as novas práticas ao significado focal que deve lhe dar sentido e propósito. Isto significa que não só é aceitável, mas também é aconselhável que uma doutrina que tome como fundamento o sentido analógico, que pretende ser normativa, demonstre o mesmo alcance e teste seus conceitos em novas práticas. A explicação de Finnis sobre a aceitação dos direitos humanos como práticas atuais é um teste e um exercício deste tipo.

\section{A CRÍTICA DE BEITZ: TÓPICOS PARA UM DEBATE}

Antes de se passar à aplicação dos pontos elencados do método da lei natural à temática dos direitos humanos, é importante elencar as críticas que são feitas ao tratamento dos direitos humanos como direitos naturais, a fim de melhor dirigir a exposição. A crítica apresentada é a realizada por Charles Beitz, em razão de sua clareza e, principalmente, porque toca no ponto metodológico a respeito de como a concepção de direitos humanos como prática 


\section{Humanos e \\ Democracia}

implica desafio à compatibilização de versões fundacionistas. Isto porque o interesse de Beitz não é de descobrir valores específicos, senão focar mais num modo de pensar aberto a esta construção (BEITZ, 2013, p. 29).

Uma vez que Beitz (2009) não se debruça sobre o direito natural enquanto proveniente da teoria da lei natural de modo extenso, sua crítica pode falhar em alguns pontos. Isso significa, principalmente, que a noção de direitos humanos enquanto prática pode, em algum nível, ser satisfeita pela teoria finnisiana. Algumas questões que Beitz critica no direito natural moderno, a teoria da lei natural também critica, tal como a inferência dogmática de direitos naturais, a pressuposição de uma ontologia que parte, de forma direta, do ser humano em abstrato para direitos deduzidos, e a crítica de sua negligência quanto à necessidade das leis positivas e demais elementos empíricos relevantes para a consecução da lei natural. É preciso, contudo, auferir se alguns pontos da crítica são cabíveis, a uma primeira vista, também à teoria da lei natural; desse modo, esses pontos tornam-se tópicos relevantes para posterior análise na teoria da lei natural finnisiana.

A crítica de Beitz (2009) direciona-se contra as teorias que equiparam direitos naturais a direitos humanos, gesto feito por Finnis. A teoria de Finnis, no entanto, não é nominalmente atacada pelo autor; então, como é possível partir de Beitz como autor responsável por apresentar as problemáticas de uma teoria jusnaturalista finnisiana a respeito dos direitos humanos? A resposta a essa questão precisa de maiores esclarecimentos.

O que Beitz (2009) critica é o que ele chama de teorias naturalistas, que correspondem a uma categoria geral desenvolvida pelo autor a englobar um maior número de teorias que fazem correspondência entre direitos humanos e direitos naturais. Sua crítica, portanto, incide contra um tipo de teoria, aquelas que apresentam um conjunto de características que ele indica; não é preciso que uma teoria apresente todas as características para ser chamada naturalista. É esperado que nenhum jusnaturalista chamasse a si próprio do modo como Beitz o categoriza, a exemplo do autor aqui tratado: o jusnaturalista John Finnis. A intenção de Beitz não é diretamente criticá-lo em particular, assim como não é de criticar qualquer autor em específico, e sim de apresentar coordenadas da crítica a um tipo de teoria como um todo que ele chama naturalista.

O que confirma esse caráter geral da teoria de Beitz é, em especial, sua afirmação de que sua crítica, de um modo geral, volta-se em menor medida para as teorias que pensam o "natural" como a busca pelos fundamentos e princípios do melhor direito idealmente concebido (BEITZ, 2009, p. 51-52), que, em Finnis, é a razoabilidade aplicada aos direitos, inclusive na avaliação dos direitos humanos. Ora, este tipo de teoria parece ser o tipo de teoria naturalista em que Finnis se baseia. Não é possível, contudo, atribuir certeza de que as críticas de Beitz não se aplicam a Finnis - e o presente artigo julga que várias poderiam ser direcionadas a ele, pois, a uma primeira análise, Finnis concordaria com algumas das características naturalistas que Beitz se propõe criticar. Do mesmo modo, o próprio Beitz $(2009$, p. 51) admite que as concepções naturalistas, moderna e pré-moderna, podem coincidir em vários aspetos. Logo, não é possível inferir seguramente que Beitz esteja dizendo que suas críticas em absoluto não podem ser dirigidas à Finnis. A atitude mais prudente de uma investigação deve ser, portanto, a de verificar se a crítica se aplica e de que forma Finnis e a teoria da lei natural respondem. 
Por apresentar apenas características gerais de teorias, e críticas envolvendo tais características, uma aproximação da análise de Beitz com a teoria de Finnis, a respeito dos direitos humanos, é uma tarefa de um artigo como este. O diálogo entre os autores é feito por meio de uma apresentação das críticas de Beitz, e das respostas de Finnis a elas. É preciso fazer um paralelo de cada uma dessas críticas pontuais com a teoria de Finnis a respeito da metodologia e dos direitos humanos, a fim de verificar como a crítica geral de Beitz às teorias naturalistas alcança, em particular, a teoria de Finnis, seja no todo ou em parte, e verificar como elas servem como argumentação que desafia novas respostas da teoria da lei natural.

Como se responderá na última parte deste artigo, por um lado, entende-se que as críticas não alcançam a teoria de Finnis da forma como Beitz (2009) as direciona às teorias naturalistas em geral. Por outro lado, entende-se que elas alcançam a teoria finnisiana não a ponto de refutá-la, mas para exigir dela novas respostas possíveis a partir da sua metodologia e aparato teórico. As considerações de Beitz (2009), se não abalam a consistência da teoria de Finnis sobre os direitos humanos, pelo menos constituem desafios que exigem respostas novas e que não podem ser contornados sem um aprofundamento da própria teoria em seus pressupostos. Por essa razão, a tarefa que se impõe é a de tomar Beitz (2009) como um autor que elenca cuidadosamente desafios à teoria finnisiana, e testar como tal teoria poderia respondê-las. Uma tarefa como esta é extremamente útil para testar a teoria dos direitos humanos de Finnis, e é isto que justifica o modo como se procede no presente artigo: primeiro apresentando a crítica de Beitz e os desafios a testar a teoria de Finnis, e, depois, a resposta deste ante esses desafios. É dessa forma que se pretende demonstrar a relação entre os autores.

Beitz (2009) expõe cada uma das problemáticas da interpretação dos direitos humanos como direitos naturais, fazendo referência aos problemas que cada uma das características dessa interpretação representa para os direitos humanos como prática internacional. Segundo Beitz (2009), a primeira característica é que "direitos naturais são requerimentos cuja força não depende de convenções morais e leis positivas da respectiva sociedade" (BEITZ, 2009, p. 52, tradução nossa); ${ }^{2}$ na segunda característica, "direitos naturais são pré-institucionais em um sentido lógico (mais do que em um sentido histórico); seus conteúdos são concebíveis independentemente de qualquer referência a características estruturais das instituições" (BEITZ, 2009, p. 52-53, tradução nossa), ${ }^{3}$ e existem numa situação pré-institucional de um estado de natureza; na terceira característica, "direitos naturais são possuídos por pessoas 'em todos os tempos e lugares' a despeito do estágio de desenvolvimento de uma sociedade e suas forças produtivas, dos detalhes da sua estrutura política, ou do conteúdo das suas tradições religiosas" (BEITZ, 2009, p. 53, tradução nossa) ${ }^{4}$; e a quarta característica é que "os direitos humanos pertencem às pessoas 'como tal' ou, em termos de uma frase comum utilizada

\footnotetext{
"natural rights are requeriments whose force does not depend on the moral conventions and positive laws of their society" (BEITZ, 2009, p. 52).

3 "natural rights are pre institutional in a logical (rather than a historical) sense: their content is conceivable independently of any reference to the structural features of institutions" (BEITZ, 2009, p. 52-53).

4 "natural rights are possessed by persons 'at all times and in all places,' regardless of the stage of development of a society and its productive forces, the details of its political structure, or the content of its religious traditions and political culture" (BEITZ, 2009, p. 53).
} 


\section{Democracia}

Humanos e

por Simmons, 'simplesmente em virtude da sua humanidade"' (BEITZ, 2009, p. 53, tradução nossa). ${ }^{5}$ Essas são características gerais, comuns a alguns tipos de teorias que esposam a versão dos direitos humanos como direitos naturais, mas nem todas as adotam na sua integralidade.

A primeira característica, para Beitz (2009, p. 53-54), é a menos problemática, porque realmente os direitos humanos têm de sustentar um nível não convencional enquanto padrão de crítica, a julgar as sociedades que se desviam de medidas humanitárias e adotam práticas radicalmente violadoras, e por isso os direitos humanos precisam, de alguma forma, superar o nível da convencionalidade. O problema dessa característica é o pressuposto ontológico que ela costuma trazer (BEITZ, 2009, p. 54) por aqueles que defendem uma interpretação por meio dos direitos naturais. Essa pressuposição ontológica aponta para uma referência de justificação exterior à prática, uma referência que a doutrina internacional dos direitos humanos não pode admitir, segundo o autor.

A segunda característica, que estabelece direitos humanos como direitos naturais num sentido pré-institucional, também tem sua plausibilidade, porque não há razão para desconsiderar esta possibilidade $a b$ initio ou, talvez, mesmo, ela seja bem-vinda (BEITZ, 2009, p. 56), principalmente porque as teorias do direito natural poderiam estabelecer dois níveis: um abstrato, que pensasse os direitos naturais a partir de uma situação de estado de natureza, e outro que já os pensasse dentro de um arranjo institucional (BEITZ, 2009, p. 56).

Nesse modelo de direito natural em dois níveis, todavia, afirma Beitz (2009), apesar de tentar incluir alguma forma mitigadora de dogmatismo, incorporando algum nível institucional, ainda existe um problema. O requisito de limitar as práticas institucionais a partir de direitos naturais exerce uma pressão a restringir o alcance do conteúdo normativo (BEITZ, 2009, p. 56), isto é, esta característica até inclui um nível institucional, mas o catálogo de direitos ainda permanece intocável pela noção de práticas. Com isso, mantém-se um sentido dogmático que dificulta pensar a construção dos conteúdos dos direitos humanos a partir da historicidade e do desenvolvimento das práticas, noção inabdicável pela doutrina internacional dos direitos humanos.

A terceira característica é altamente criticada por Beitz (2009). Para o autor, é difícil pensar que um direito humano, no modo como ele é formulado na doutrina internacional dos direitos humanos, possa ser válido igualmente para todas as épocas e lugares. Como o autor salienta, "considere, por exemplo, os direitos à seguridade social ou, novamente, a uma educação livre e elementar (artigos 22 e 26) (...) seus criadores não poderiam ter intencionado que a doutrina dos direitos humanos se aplicasse, por exemplo, à Grécia antiga" (BEITZ, 2009, p. 57). ${ }^{6}$ No tópico final, quando se explicar a teoria finnisiana da lei natural, se criticará também essa posição dogmática, e se responderá, contudo, sem dar uma exposição unicamente baseada em prática.

\footnotetext{
"human rights belong to persons 'as such' or, in the customary phrase used by Simmons, 'simply in virtue of their humanity'” (BEITZ, 2009, p. 53).

6 "consider, for example, the rights to social security or, again, to free elementary education (arts. 22, 26). (...) its framers could not have intended the doctrine of human rights to apply, for example, to the ancient Greeks" (BEITZ, 2009, p. 57).
} 
As críticas correspondentes às três primeiras características, no entendimento de Beitz, referem-se mais caracteristicamente ao direito natural moderno, que é a primeira forma de entender o natural dentro do seu plano de exposição. Isso, todavia, isso é diferente quanto à quarta característica, de que há direitos humanos em virtude de sua própria humanidade, que Beitz afirma se aplicar explicitamente mesmo a uma versão de direito natural semelhante à de Finnis (2009, p. 59).

A quarta característica manifesta-se em ambas as formas do direito natural, aquela mais moderna e a outra mais clássica. Beitz (2009, p. 59) expõe essa perspectiva - de que a simples característica de pessoa como tal justifica por que alguém tem direitos humanos de dois modos: a perspectiva da demanda (demand side) e a perspectiva do suporte (supply side). A perspectiva da demanda busca explicar por quais razões se deveria proteger os direitos humanos como coisas boas para os beneficiários, enquanto a perspectiva de suporte tenta explicar por que uma classe de agentes deveria proteger beneficiários de modo a tornar obrigatório e coercitivo os direitos humanos (BEITZ, 2009, p. 59).

As teorias do direito natural, de ambos tipos, tratam que os direitos humanos são aplicados a todos os seres humanos e não dependem da cultura. A ideia fundamental é que há interesses comuns básicos que explicam o porquê de direitos humanos, fundados naqueles interesses, devem ser protegidos, e que isso deveria ser relevante a ponto de exigir a normatividade em relação aos agentes, sejam eles instituições do Estado ou agentes internacionais independentes, como as ONGs. Fundando-se nesses interesses básicos, as teorias do direito natural, em geral, segundo Beitz (2009, p. 64-65), não precisam recorrer a uma ordem global ou à descrição de suas práticas, isto é, não retiram o conteúdo dos direitos humanos desde o modo emergente como eles vão se dando, e sim a partir de uma visão fundacionista.

Estes são alguns dos desafios que Beitz (2009, p. 65) elenca serem imputáveis às teorias do direito natural na perspectiva da demanda: (1) elas não se referem à função discursiva dos direitos humanos na prática global; (2) as teorias do direito natural limitam o alcance dos direitos humanos porque não dão atenção para a função discursiva; (3) as teorias do direito natural chamam e limitam os direitos humanos a uma lista, muitas vezes, ausente na doutrina internacional dos direitos humanos; e (4) quando as práticas dos direitos humanos confrontam com as teses teóricas dos direitos humanos, há uma tendência às teorias do direito natural em sustentar a reforma das práticas, e não a de tentar aceitar a prática e incorporá-las na teoria (BEITZ, 2009, p. 65-67).

A perspectiva de suporte, que explica a quem os direitos humanos direcionam-se, não importa à questão aqui debatida, principalmente porque, tendo este artigo um fundo de discussão metodológica e sua aplicação ao problema dos direitos humanos. Logo, o ponto central continua a ser aquela situação em que se expõe propriamente o porquê de se ter direitos humanos e como também os pressupostos explicam a assunção das práticas. Passa-se, então, à resposta que a teoria da lei natural em Finnis tem a dar a alguns desses problemas, principalmente em não se afastar da noção de práticas e tentar explicar como tal teoria parece entender essa necessidade de incorporação, por meio do esforço em afastar esses problemas. 


\section{Humanos e \\ Democracia}

\section{APLICAÇÃO DOS PRESSUPOSTOS E MÉTODOS DA LEI NATURAL AOS DIREITOS HUMANOS}

Tendo explicado as críticas de Beitz (2009) à concepção naturalista de direitos humanos, chega-se à parte deste trabalho em que se oferecem respostas a esse problema desde a metodologia e pressupostos mais fundamentais da teoria da lei natural em Finnis. O interesse nas respostas que se seguem é tomar as considerações de Beitz (2009) como um padrão geral do que se pode pontualmente criticar nas teorias naturalistas, e realizar um exercício especulativo de como algumas dessas críticas podem ser tomadas para criticar também a teoria da lei natural finnisiana. Frisa-se, portanto, que a intenção em partir de suas críticas é uma escolha metodológica do trabalho em tomá-las como tópicos para uma análise de problemas relevantes e, por meio de respostas às críticas, incentivar a teoria a desenvolver melhor sua relação com a aceitação das práticas dos direitos humanos.

A primeira crítica de Beitz (2009) foi que os direitos humanos realmente precisam superar a convencionalidade e a cultura para construir um padrão de crítica às práticas, mas o erro das teorias naturalistas seria tomar um pressuposto ontológico, que é uma referência exterior à prática, referência esta que a doutrina internacional dos direitos humanos não poderia assumir. Essa crítica é completamente afastada em Finnis (2011c), porque, em Lei natural e direitos naturais (doravante chamada LNDN) (FINNIS, 2011c), sua metodologia e pressupostos entendem que não é correto começar uma teoria do direito natural desde uma descrição metafísica ontológica do ser humano e daí derivar os direitos. Pelo contrário, Finnis considera que, se fizesse isso, realmente uma teoria da lei natural incorreria na falácia naturalista.

Sua obra, contudo, não é apenas assentada sobre o LNDN. Nesta obra, Finnis parece realmente interessado em afastar o fundo metafísico de sua teoria, o que, de algum modo, por si só seria suficiente para afastar a questão de Beitz. Se, todavia, por um lado sua obra LNDN tem essa característica, na obra Aquinas (FINNIS, 1998, p. 176), quando ele debate a dignidade humana, parece fazer uma incorporação de elementos metafísicos e ontológicos. A própria descrição de dignidade humana, que é importante para os direitos humanos em Finnis, parece apontar para um grau de pressuposição ontológica (FINNIS, 1998, p. 178-179).

A descrição da dignidade em Finnis é entendida a partir de uma unidade das capacidades do ser humano enquanto tal, que, realmente, tem um sentido metafísico ou ontológico, e é a noção de alma (anima) que está no cerne dessa unidade (FINNIS, 1998, p. 178-179). Isso, porém, não significa, em si, que os direitos humanos sejam, na doutrina de Finnis, dependentes de uma ontologia. A dignidade gera uma exigência de justiça, mas não é a descrição ontológica do homem que explica por que se tem direitos humanos, e sim a dignidade de ser pessoa; nas próprias palavras de Finnis, "seria um equívoco afirmar que nós temos estes direitos [direitos humanos] porque somos humanos. É preferível afirmar que cada um os possui porque todo membro individual da espécie tem a dignidade de ser pessoa" (FINNIS, 1998, p. 176). Apesar, portanto, de Aquinas (FINNIS, 1998) ser uma obra em que Finnis já insere mais elementos ontológicos e metafísicos, essa pressuposição não é diretamente um fundamento para os direitos humanos, e sim ela é um indicador da nossa condição racional que exige interesses específicos mais fundamentais que baseiam a exigibilidade de um direito humano como se entende (ROHLING, 2015). Desse modo, a ontologia não desempenha uma função de gerar deveres; é a epistemologia que explica como surgem deveres: 
Eles sustentam que não há inconsistência aqui e que sua concepção teleológica de natureza não produz enunciados morais normativos. Isto é sustentado por meio de uma distinção rigorosa entre epistemologia e ontologia. Os jusnaturalistas sustentam que, epistemologicamente falando, é impossível inferir a existência de bens básicos a partir da natureza humana. Todavia, ontologicamente falando, os bens básicos são fundados na natureza. Uma vez que tem sido crítica de Hume que não deveríamos inferir normas a partir de fatos, Finnis e Grisez pensam que podem evitar este ônus fazendo uma distinção entre epistemologia e ontologia. Embora normas tenham fundamento na natureza, eles não inferem normas a partir da natureza (WESTERMANN, 1998, p. 254, tradução nossa). ${ }^{7}$

A segunda crítica que Beitz apresenta, e que pode ser norteadora para entender os direitos humanos em Finnis, é aquela que critica os direitos naturais por supostamente serem pré-institucionais, em razão de postularem um estado de natureza, e, com isso, serem de um tipo que mantém um catálogo de direitos humanos restritos e fechados às influências que poderiam ser inferidas das práticas. A primeira parte dessa crítica evidentemente não se aplica à teoria da lei natural de Finnis, porque ele ressalta que a característica de uma teoria do direito natural fazer referência ao estado de natureza é típica das teorias modernas do direito natural, e não da teoria clássica tomista a que Finnis se vincula. Contudo, uma vez excluída a parte que não se aplica, a crítica ainda tem pertinência suficiente para desafiar a teoria de Finnis.

Os direitos humanos na teoria de Finnis realmente, em algum nível, são pré-institucionais. Finnis equipara os direitos humanos com os direitos naturais (FINNIS, 2011c, p. 198), e isso significa que é preciso aplicar o método dos direitos naturais para entender os direitos humanos. Os direitos naturais, na teoria finnisiana, são os direitos derivados por modo de conclusão desde os bens básicos, assumindo uma forma de prescrição jurídica que é o que de mais fundamental se vincula ao direito. Isso ele considera ser a parte necessária de todo sistema jurídico, pois se remete aos propósitos mais fundamentais do direito, apresentado em alguns momentos passados como ius gentium, em outros momentos como ius cogens erga omnes e agora como direitos humanos fundamentais (FINNIS, 2007, p. 95). Os direitos humanos, nesse sentido, são pré-institucionais, porque sua dedução provém diretamente dos bens básicos, sem passar pela percepção das práticas, ou pela deliberação política que lhe daria forma. Essa argumentação, no entanto, ainda está incompleta.

Os direitos naturais, que são direitos humanos, não são atemporais como acusados de ser, ou não implicam numa concreção que não faça sentido para as práticas. Isso implica que, para entender os direitos humanos em Finnis, é preciso distinguir e conciliar dois lados, um em que sua fundação é mais substancial, e outra em que há maior aceitação das práticas. O próprio Beitz $(2009$, p. 56$)$ antecipou que uma das possíveis respostas das teorias do direito natural à sua crítica seria o recurso de separar dois níveis de argumentação: um que pensasse de modo mais abstrato os direitos humanos em seu sentido mais relacionado com

\footnotetext{
"They maintain that there is no inconsistency here and that their teleological conception of nature does not give rise to moral 'ought'-statements. This is argued by means of a rigorous distinction between epistemology and ontology. The natural lawyers assert that, epistemologically speaking, it is impossible to infer the existence of basic goods from human nature. But ontologically speaking, the basic goods are grounded in nature. Since it has been Hume's criticism that we should not infer norms from facts, Finnis and Grisez think that they can avoid that charge by making a distinction between epistemology and ontology. Although norms are grounded in nature, they do not infer norms from nature" (WESTERMANN, 1998, p. 254).
} 


\section{Democracia}

Humanos e

os direitos naturais, e outra que já o reflete dentro dos arranjos institucionais. Beitz antecipa essa resposta da teoria do direito natural, mas não a supera, porque de fato essa resposta demonstra como o direito natural pode ter um caráter institucional. Ele tenta corrigir isso afirmando que, ainda, sim, seria persistente o problema do catálogo de direitos ser limitado; contudo, este é outro problema, e não o que versa acerca da institucionalidade dos direitos naturais.

As considerações metodológicas feitas no primeiro capítulo são importantes para este problema. Primeiro é preciso considerar a aceitação das práticas. Quando Finnis refere-se a direitos humanos, não só ressalta que eles são direitos naturais, mas enfatiza que eles, de alguma forma, estão já plasmados nas principais declarações de direitos humanos, principalmente na Declaração Universal dos Direitos Humanos de 1948 (FINNIS, 2011c, p. 214). Nessa afirmação fica claro que o interesse de Finnis não é o de demitir a importância das instituições e práticas para os direitos humanos; pelo contrário; o seu interesse é, antes, o de sempre reconduzir as instituições e práticas para a melhor realização do florescimento humano, mas é preciso aceitar prudencialmente as imperfeições que porventura as instituições internacionais tenham, porque a realização dos interesses mais básicos nunca é feita de modo perfeito (GREEN, 2013).

Finnis, portanto, incorpora, claramente, as práticas internacionais de direitos humanos, principalmente tendo como pilar a DUDH de 1948. Vários dos artigos nela presente apresentam importância fundamental:

Dentre os direitos proclamados na Declaração Universal estão a vida, a liberdade, segurança pessoal (Artigo 3), igualdade perante a lei (Artigo 7), privacidade (Artigo 12), casamento e proteção da vida familiar (Artigo 16), propriedade (Artigo 7), segurança social e a "realização, através dos empreendimentos nacionais e internacionais de cooperação... dos direitos econômicos, sociais e culturais indispensáveis para a dignidade [de todos] e o livre desenvolvimento de sua personalidade" (Artigo 22), participação no governo (Artigo 21), trabalho, proteção contra o desemprego, remuneração adequada pelo trabalho (Artigo 23), descanso e lazer (Artigo 24), "padrão de vida adequado para... ter saúde e bem-estar..." (Artigo 25), educação (Artigo 26), fruição das artes e um compartilhamento dos benefícios dos avanços científicos (Artigo 27), e "uma ordem social e internacional na qual os direitos e liberdades estabelecidos nesta Declaração possam ser completamente realizados" (Artigo 28). Quando analisamos esta lista, nós percebemos o que o "manifesto" moderno da concepção de direitos humanos valoriza (FINNIS, 2011c, p. 214, tradução nossa)..$^{8}$

\footnotetext{
"For amongst the rights proclaimed in the Universal Declaration are life, liberty, security of person (Article 3), equality before the law (Article 7), privacy (Article 12), marriage and protection of family life (Article 16), property (Article 17), social security and the 'realization, through national effort and international co-operation ... of the economic, social and cultural rights indispensable for [everyone's] dignity and the free development of his personality' (Article 22), participation in government (Article 21), work, protection against unemployment, favourable remuneration of work (Article 23), rest and leisure (Article 24), 'a standard of living adequate for... health and well-being...' (Article 25), education (Article 26), enjoyment of the arts and a share in the benefits of scientific advancement (Article 27), and 'a social and international order in which the rights and freedoms set forth in this Declaration can be fully realised' (Article 28). When we survey this list we realize what the modern 'manifesto' 22 conception of human rights amounts to" (FINNIS, 2011c, p. 214).
} 
Finnis apresenta nesta afirmação duas informações importantes: a primeira é que é em um Tratado real, proveniente da construção pelas práticas, que podemos encontrar orientações adequadas sobre os aspectos mais relevantes da vida humana e os direitos mais fundamentais, e não em uma ideia abstrata ou a partir de filósofos ilustrados. A segunda informação é que os direitos humanos apresentam-se, de modo especial, enquanto manifesto moderno, e mesmo assim a teoria da lei natural continua a enxergar neles o ponto de partida mais relevante. Finnis chega mesmo a afirmar que tais direitos humanos da Declaração são formas de esboçar os contornos do bem comum (FINNIS, 2011c, p. 214). Finnis, portanto, não se distancia das práticas dos direitos humanos; ao contrário, busca aproximar-se delas.

O método do caso central de Finnis contribui para essa compreensão. O caso central do direito positivo é aquele que mais se aproxima do direito natural, e nesse caso os direitos humanos. É preciso aceitar, todavia, que o caso central nunca vai se realizar plenamente, de onde se conclui que a teoria da lei natural aceita casos desviantes de direito como normativos, em prol de sua realização prática efetiva mesmo que num nível mediano. Essa é a razão pela qual a desobediência civil não é indiscriminadamente apoiada pelo direito natural, porque, ainda que algumas leis sejam desviantes, é preciso reconhecer que algum bem da lei elas continuam a realizar, de sorte que o seu descumprimento importaria em um dano maior. Isso ocorre porque a obrigação moral de conformidade sobre as leis positivas é apenas presumível, e não retira toda sua força da lei natural (FINNIS, 2007, p. 96).

Os direitos humanos que Finnis considera que assim merecem ser chamados de modo central, são aqueles que coincidem com os direitos naturais, isto é, não necessariamente aqueles provenientes das práticas - apesar de não desprezar sua importância -; são, antes, aqueles direitos humanos cujo conteúdo provém de uma derivação por conclusão direta desde a lei natural e, principalmente, dos bens básicos que a integram. A primeira vista, isso parece significar que os direitos humanos, segundo Finnis, não comportam aspectos de práticas, mas essa crítica não é completamente verdadeira. De alguma forma, as práticas e formas institucionais precisam ser avaliadas e ratificadas como direitos humanos. Como ocorre com a positivação, entretanto, a necessidade de ensejar alguma ordem não pode esperar, de modo que, mesmo alguns direitos humanos que não estejam no seu caso central, isto é, que não sejam conclusões diretas dos direitos naturais, sendo eles formas defectivas que ainda guardam alguma relação com o que de mais fundamental há nos direitos, não podem ser simplesmente descartados como não direitos humanos. Isso demonstra que a teoria da lei natural finnisiana possui um grau de realizabilidade institucional e de aceitação das práticas, porque não é uma teoria dogmática do direito natural, como são as teorias modernas jusnaturalistas.

Quanto à institucionalidade especial da ordem internacional e dos direitos humanos que dela se valem para sua execução, Finnis (2011c) não sustenta que a institucionalidade valha apenas para a autoridade das comunidades internas a um Estado-nação; pelo contrário, ele afirma que "há relações entre pessoas que transcendem as fronteiras de todas as poleis, reinos, ou Estados" (2011c, p. 149-150. Tradução nossa). ${ }^{9}$ Logo, Finnis reconhece, evidentemente, que o Estado-nação não é uma comunidade completa, no sentido de ser tão autossuficiente quanto se julgava ser; o bem comum é contemporaneamente dependente 


\section{Democracia}

Humanos e

dos direitos humanos, pois existe um bem de toda a humanidade, e Finnis (2011c, p. 155-156) explicita bem a incompletude do Estado-nação para esse bem comum total. Com efeito, o período contemporâneo explicita, melhor do que qualquer outra época, que as relações entre as pessoas, que ultrapassam as fronteiras, mostram-se verdadeiramente globais, e, principalmente, que os direitos não são apenas os proclamados internamente pela institucionalidade do Estado, mas há uma institucionalidade internacional a ser realmente levada em conta, e os direitos humanos por ela promovidos são relevantes. Finnis não rejeita, portanto, a institucionalidade dos direitos naturais, tampouco a institucionalidade da ordem internacional; antes, pela teoria da lei natural, explicita sua relevância.

A terceira crítica também é respondida pelas considerações anteriores. Os direitos humanos, enquanto direitos naturais, isto é, na sua formulação mais conclusiva e aproximada dos bens básicos, realmente são independentes de tempo e lugar. Não é apenas esta forma, contudo, que importa para a teoria da lei natural. Assim como as leis positivas são indispensáveis para a ordem jurídica, e é assim porque somente a lei humana pode cumprir uma função coercitiva, os direitos humanos, nas formas de tratados e declarações em geral, e suas concreções históricas, precisam ser assumidos pela teoria da lei natural. Isso é uma necessidade metodológica: o caso central precisa, ao mesmo tempo, aceitar como normativa algumas formas defectivas e análogas, algumas práticas ligeiramente desviantes, aquelas que são direitos humanos apenas em analogia, bem como acreditar que os direitos humanos, em suas formas temporais, não diretamente direitos naturais, em algum nível, guardam sua normatividade.

Engelmann (2007) faz uma análise da lei natural a partir de Finnis de um modo interessante, integrando sua teoria com a historicidade. ${ }^{10} \mathrm{O}$ autor ressalta que são os princípios da lei natural que não estão sujeitos à histórica, sendo, por isso, ahistóricos (ENGELMANN, 2007, p. 151). O modo, porém, como a lei positiva, e mesmo os tratados internacionais em geral e, em particular, os de direitos humanos, vão percebendo quais direitos devem resguardar, mostra historicidade e decisão prudencial. A teoria da lei natural, diferente do direito natural moderno dogmático, pretende oferecer os princípios para as decisões razoáveis, inclusive para orientar os direitos humanos e as práticas jurídicas globais. Em nada pretende, de antemão, todavia, impedir a influência prudencial das circunstâncias históricas. Como afirma Kaufmann (2000, p. 43 apud ENGELMANN, 2007, p. 140),

que o Direito seja histórico não significa que, em qualquer parte, se desenvolve de forma reservada no tempo, senão que o caminho deve ter um objetivo totalmente determinado, o caminho do Direito para o Direito Natural. O Direito natural e a historicidade, portanto, não são inimigos um do outro, a historicidade do Direito lhe conduz a um maior esclarecimento ao Direito Natural, com vistas a alcançar o inalcançável, o que é possível justamente aqui e agora: o Direito jurídico temporal.

Finnis é um dos autores do direito natural mais consciente de que a lei natural fornece os princípios e não já as conclusões específicas do que deve ser feito. A aceitação das práticas dos direitos humanos, dos arranjos globais institucionais como factualmente indeléveis, somente são possíveis para uma teoria do direito natural que entendeu que a ahistoricidade da

\footnotetext{
${ }^{10}$ Tal caráter perpassa por toda sua obra, uma vez que, como o próprio título da obra sustenta, Engelmann (2007) pretende fornecer uma abordagem hermenêutica do direito natural.
} 
lei natural não tolhe a historicidade dos direitos humanos, dos tratados; antes orienta fornecendo os princípios para um posterior julgamento. Engelmann acredita que Finnis entendeu que não existe oposição instrínseca entre direito natural e direito positivo, ou direitos humanos, isto é "o direito natural não precisaria ser visto como outra parte da moeda" (ENGELMANN, 2007, p. 142) ante o direito positivo ou os tratados de direitos humanos.

A lei natural, portanto, não se opõe à historicidade dos direitos humanos; antes "estes princípios da lei natural possibilitam o julgamento da história humana" (ENGELMANN, 2007, p. 152), e, consequentemente, dos direitos humanos na história. No dizer de Castanheira Neves (2003), o direito natural e o direito positivo devem convergir, de tal modo que se possa falar do direito positivo como direito natural vigente (p. 45-46); parafraseando-o, o direito natural e os direitos humanos, enquanto provenientes de tratados e arranjos institucionais globais, deveriam convergir a ponto de que os direitos humanos fossem, em verdade, direitos naturais vigentes na ordem global.

Do mesmo modo, o que atesta essa aceitação das práticas dos direitos humanos na ordem internacional (este "direito natural vigente na ordem global) é o modo como Finnis, por exemplo, opta por analisar a autoridade dos costumes (FINNIS, 2011c, p. 238-245). O debate é longo, e não é preciso entrar em maiores detalhes. Finnis (2011c, p. 243-244) vai sustentar que não é suficiente que haja argumentos morais que justifiquem a autoritatividade de um costume; é preciso de uma autoritatividade legal: "A autoritatividade geral do costume depende do fato de que a formação do costume tenha sido adotada na comunidade internacional como um método apropriado de produção de regras" (FINNIS, 2011c, p. 244, tradução nossa). ${ }^{11}$ A partir disto, dado que os direitos humanos dependem dos costumes, Finnis deixa claro que sua teoria dos direitos humanos depende claramente da prática e do framework internacional, como ele próprio afirma (FINNIS, 2011c, p. 244).

Quanto à última crítica de Beitz, que este entende ser diretamente também aplicável a uma teoria do direito natural do tipo adotada por Finnis, é preciso entender que seu ataque tem uma descrição inadequada e insuficiente para derrubar a consistência da teoria de Finnis, principalmente pelas razões já apresentadas a respeito de sua incorporação institucional de práticas. A crítica fundamental, apontada por Beitz (2009), é que, para aqueles que sustentam que os direitos humanos se estendem a todos em razão da sua humanidade como tal, os direitos humanos independem da cultura e não precisam fazer referência a uma ordem global.

Essa última afirmação não se aplica a Finnis porque sua teoria reconhece o papel indelével das formas concretas da lei humana, do framework das práticas e costumes internacionais já explicados nos parágrafos anteriores, e dos tratados internacionais, para a coerção dos direitos naturais, bem como na sua melhor especificação (DUKE, 2013). Por isso os direitos humanos, para uma teoria da lei natural, tanto não independem completamente da cultura quanto também não dispensam a relevância da ordem global. Talvez Beitz (2009) esteja fazendo referência mais ao conteúdo dos direitos humanos, todavia sua crítica parece estar mais abrangente do que isso. É preciso frisar que não somente a temática do conteúdo é

\footnotetext{
11 "the general authoritativeness of custom depends upon the fact that custom-formation has been adopted in the international community as an appropriate method of rule-creation" (FINNIS, 2011c, p. 244).
} 


\section{Humanos e \\ Democracia}

importante para os direitos humanos; sua efetivação também o é, e por isso a teoria da lei natural ressalta a relevância das formas concretas de lei emanadas por uma autoridade, isto é, considera, sim, relevante fazer referência em algum nível à ordem global internacional.

Uma última colocação de Beitz (2009) dedica-se a atacar uma suposta tendência das teorias do direito natural, inclusive a finnisiana, de afastar um direito como direito humano em razão da sua colisão com a concepção que essas teorias sustentam de direitos naturais, isto é, quando uma prática ou instituição diz que algo é direito humano, mas isto não é abarcado como direito natural; então, segundo Beitz (2009), uma teoria desse tipo tenderia a rejeitá-la como direito humano. Essa visão é um pouco exagerada, porque, mesmo para os defensores modernos do direito natural (que são mais dogmáticos), de alguma forma cabe às instituições a interpretação da conformidade dos direitos com os direitos humanos, de modo que há uma dialética entre essas instâncias, até porque as contingências dão respostas diferentes acerca da conformidade ou não com o direito natural.

É preciso reconhecer que realmente a teoria da lei natural visa a realizar, sim, esse tipo de crítica sobre o direito instituído; nesse caso o direito humano instituídos pelas práticas, Tratados e instituições internacionais. A tendência crítica, contudo, não desabona a capacidade de explicar a incorporação de práticas ou uma certa visão institucional, principalmente porque a própria posição de Beitz (2009, p. 105-106) é a de que uma teoria dos direitos humanos também precisa saber ter uma posição crítica a respeito de alguns direitos humanos, de modo que não pode ser absolutamente descritiva e acrítica. Isso significa que uma concepção baseada em práticas de Beitz (2009) não está menos disposta a criticar as práticas defectivas dos direitos humanos do que uma concepção baseada na lei natural.

Por todo o exposto, fica claro que Finnis não dispensa as práticas dos direitos humanos; antes a incorpora, tanto na sua linguagem de direitos quanto na aceitação da institucionalidade da ordem global dos direitos humanos. Disto, há alguns avanços que se pode observar a partir da inserção da teoria da lei natural nesse debate de incorporação de práticas.

Como ressalta Engelmann (2007), a teoria em Finnis não é uma reflexão sobre as versões do direito natural. A lei natural é uma realidade dos princípios práticos, que, de formas diversas, servem à ética, política e ao direito; com efeito, tais princípios alcançam os direitos humanos de um modo especial. Dessa maneira, a teoria prática da lei natural fornece uma riqueza em instrumentos teóricos e práticos para descrever e avaliar os direitos humanos. Por exemplo, os bens básicos podem funcionar como um balizador para identificar os direitos humanos mais relevantes e urgentes. Isso não significa que toda teoria da lei natural seja estrita em aceitar apenas os direitos humanos que estejam dentre estes bens; contudo, pode-se propor uma hierarquia de direitos humanos mais importantes e de outros menos centrais, por meio mesmo da aplicação do método do caso central e caso periférico.

Outro importante avanço é quanto ao método enquanto tal. Isto, de alguma forma, já foi evidenciado neste artigo, mas pode voltar a ser destacado. A metodologia do caso central e do sentido focal, e a aplicação da analogia aos direitos humanos, fornece um instrumento teórico capaz de avançar tanto na descrição de fenômenos quanto na sua avaliação. As bases metodológicas da lei natural são tanto descritivas quanto avaliativas. Os direitos humanos ganham com essas reflexões, na medida em que, dentro da pluralidade de direitos, os direitos humanos pretendem ser aqueles mais fundamentais (mais centrais) para toda vida humana, 
de tal modo que, para isto, é preciso uma linguagem que avalie que há direitos mais fundamentais que outros, e que descreva os centrais e os periféricos, avaliando-os simultaneamente. A teoria da lei natural propicia este método para sustentar que os direitos humanos são mais centrais que o direito positivo ou um comando emanado de uma autoridade, e não podem ser preteridos por estes.

Estritamente quanto às implicações práticas, pode-se ressaltar a função que Finnis atribui aos direitos humanos. Finnis (2011c, p. 236) sustenta que os direitos humanos integram, diretamente, o bem comum. $E$ isto não é apenas uma assertiva teórica; uma vez que tal é a sua função; os direitos humanos também são a base da fundamentação da autoridade política, dos comandos do Estado e da produção das leis positivas, pois é o bem comum que é a justificação da autoridade política. Em tempos em que os direitos humanos se tornam cada vez mais consensuais, e não apenas aceitos convencionalmente, mas reconhecidos como fonte de justiça, uma teoria que explica como eles integram a justificação da autoridade ganha proeminência.

Com efeito, os direitos humanos, a partir da teoria da lei natural, tomam a função de serem avaliadores e críticos dos Estados, e fornecem para as instituições globais de direitos humanos instrumentos conceituais e categorias para fazer essas análises. Do mesmo modo, como Finnis pensa os direitos humanos como requisitos do bem comum político, logo sua teoria tem maior facilidade de explicitar o alcance interno à política Estatal. Os direitos humanos não são apenas um mecanismo de intervenção na soberania para evitar a violação a direitos; eles são justificadores da autoridade interna. Algumas práticas dos direitos humanos precisam dessa correlação, a exemplo do chamado controle de convencionalidade. Uma vez que os direitos humanos são vistos por Finnis com tamanha importância para a integração da política interna de um Estado para com o bem comum de toda a humanidade, abrem-se caminhos para facilitar práticas que visam a integrar o global e o local em torno da justiça dos direitos humanos.

\section{CONCLUSÃO}

O presente artigo expôs como a teoria de Finnis explica a incorporação dos direitos humanos como prática emergente, apesar de sua fundamentação na teoria da lei natural. 0 itinerário até a resposta precisou passar, principalmente, por pontos da metodologia da lei natural em Finnis, mormente porque o problema do artigo versa sobre as bases do modo de raciocínio da teoria da lei natural e sua maneira de proceder nas justificativas que apresenta. Esses pontos metodológicos foram, em especial, o método do caso central, a distinção entre derivação por conclusão e determinação, a tendência de uma teoria da lei natural crítica, mas também descritiva que exige a aceitação de práticas, e as práticas dos direitos humanos principalmente.

Como forma de elencos e etapas à pergunta, elegeu-se a obra de Beitz para apresentar as dificuldades que uma teoria naturalista tem em incorporar práticas. A partir de suas críticas, submeteu-se os problemas elencados à teoria de Finnis, utilizando as categorias metodológicas apresentadas na primeira parte para mostrar como o autor explica o caráter institucional dos direitos humanos e a aceitação das práticas, mesmo tendo uma teoria fundada na lei natural. Embora Finnis não tenha em sua obra dado diretamente uma exposição acerca da 


\section{Humanos e \\ Democracia}

incorporação das práticas atuais dos direitos humanos, foi possível expor como uma teoria da lei natural pode fazer a incorporação de tais práticas lançando mão de seus pressupostos e recursos metodológicos, sobretudo de pesquisa social. Ainda que sua teoria permaneça crítica a determinadas formas de direitos humanos, ela tem recursos para explicar como a normatividade de tais formas se mantém, e como a analogia e o seu método do caso central podem servir para uma teoria dos direitos humanos fundada em direitos naturais que seja menos dogmática do que aquela diretamente criticada por Beitz em sua obra.

Desse modo, a pesquisa não representou uma pura e simples defesa da teoria da lei natural e de Finnis ante as críticas de Beitz. De fato, reconheceu-se que as críticas têm pertinência, que são problema que devem ser assimilados para que a teoria da lei natural se renove. As teorias do direito natural várias vezes recaem em um fundacionismo, isto é, partem de preconcepções metafísicas, antropológicas ou principiológicas, e não fornecem um aparato para pensar os direitos humanos desde as práticas; mas é esta visão que se quer superar.

Pensar direitos humanos como direitos naturais, como demonstrou-se, pode ser mais do que impor um direito supra-histórico conhecido; pelo contrário, pode significar que os princípios da lei natural sejam norteadores para as práticas históricas. É este modelo que se julga ser o adotado por Finnis, e, a partir das críticas de Beitz, pretendeu-se avançar na direção de que a teoria da lei natural tem de preterir uma análise dogmática do direito natural, e, uma vez que se considerou equivalente direitos naturais e direitos humanos, é preciso olhar não somente para os princípios do primeiro, mas para as práticas do segundo.

Uma crítica a uma teoria não serve apenas para refutá-la, mas talvez para fazê-la repensar o uso de seus próprios pressupostos. A crítica de Beitz não refuta a teoria da lei natural como um todo, mas serve para orientar melhor as interpretações acerca da lei natural. Sobre esta há inúmeras interpretações; umas mais dogmáticas, mais alinhadas a uma visão supratemporal e supralocal dos direitos humanos, e outras que consideram que as práticas podem ser um ponto de partida viável, sem abandonar os princípios. Uma crítica consistente, como a de Beitz, serve para chamar a atenção mais para o segundo tipo de interpretação e revelar os problemas da primeira. Fazer essa interpretação da teoria da lei natural, como o presente artigo pretendeu, exige estruturar a metodologia de Finnis para a aceitação das práticas, de modo que suas pressuposições de caso central e sentido focal, por exemplo, talvez precisem ser menos dogmáticas e mais dialógicas com as formas sociais das práticas dos direitos humanos e instituições que se apresentam concretamente a elas.

Com efeito, não é apenas uma questão de interpretação, mas isso guia a teoria da lei natural a se empenhar cada vez mais no sentido das práticas, e isso exige, por sua vez, inovação da teoria a partir de seus pressupostos. Por exemplo, se deu mais atenção à normatividade dos casos periféricos, isto é, do reconhecimento que as formas históricas de direitos humanos menos próximas dos direitos naturais, mas ainda assim não completamente afastadas, podem ter força normativa. Uma visão mais dogmática do direito natural não tenderia a essa interpretação; tenderia, logo, a acusar tais direitos humanos como ideológicos e desarrazoados. Ao contrário, a crítica de Beitz, tomada pela lei natural de Finnis, tende a sensibilizá-la para a historicidade dos direitos humanos, reconhecendo a normatividade. O presente artigo 
entende que a nova teoria da lei natural deve caminhar, portanto, em direção a uma teoria efetivamente prática dos direitos humanos, por meio de uma interpretação mais compreensiva com as práticas e menos dogmática.

\section{REFERÊNCIAS}

AIYAR, S. The problem of law's authority: John Finnis and Joseph Raz on legal obligation. Law and Philosophy, v. 19, p. 465-489, jul. 2000.

BEITZ, Charles. The Idea of Human Rights. New York: Oxford University Press, 2009.

BEITZ, Charles R. From Practice to Theory. Constellations, v. 1, n. 20, p. 27-37, mar. 2013.

CASTANHEIRA NEVES, A. A crise actual da filosofia do direito no contexto da crise global da filosofia: tópicos para a possibilidade de uma reflexiva reabilitação. Boletim da Faculdade de Direito de Coimbra. Coimbra: Coimbra, 2003.

CORREAS, Carlos Massini. Derechos Humanos y Bienes Humanos. In: Teoría del Derecho y Derechos Humanos. Peru: ARA Editores, 2011. p. 25-55.

CORREAS, Carlos Massini. La concepción normativa del gobierno del Derecho: nuevas objeciones al rule of law y una respuesta desde las ideas de John Finnis. Persona y Derecho, vol. 73, p. 203-230, fev. 2015.

CROWE, J. Natural Law Theories. Philosophy Compass, v. 11/2, p. 91-101, fev. 2016.

DUKE, George. Finnis on the Authority of Law and the Common Good. Legal Theory. v. 19, p. 44-62, mar. 2013.

ENGELMANN, Wilson. Direito natural, ética e hermenêutica. Porto Alegre: Livraria do Advogado, 2007.

FINNIS, John. Aquinas: Moral, Political and Legal Theory. Oxford: Oxford University Press, 1998.

FINNIS, John. Direito natural em Tomás de Aquino: sua reinserção no contexto do juspositivismo analítico. Trad. Leandro Cordioli e revisão Elton Somensi de Oliveira. Porto Alegre: Sergio Antonio Fabris Editor, 2007.

FINNIS, John. Human rights and their enforcement. In: Human rights and Common - Collected essays v. III. Oxford: Oxford University Press. 2011a. p. 19-467.

FINNIS, John. Limited Government. In: Human rights and Common - Collected essays vol. III. Oxford: Oxford University Press. 2011b. p. 83-107.

FINNIS, John. Natural Law and Natural Rights Good. 2. ed. New York: Oxford University Press, 2011c.

GREEN, Leslie. The Nature of Limited Government. In: GEORGE, R. P.; KEOWN, J. (ed.). Reason, Morality, and Law: The Philosophy of John Finnis. Oxford: Oxford University Press, 2013. p. 186-203.

KAUFMANN, Arthur. Filosofia do direito. Tradução Antônio Ulisses Cortês. Lisboa: Fundação Calouste Gulbenkian, 2004.

MURPHY, M. The Common Good. Review of Metaphysics, v. 59, p. 133-164, set. 2005.

ROHLING, Marcos. Pluralismo e direitos: a necessidade da ordem jurídica para o bem comum em Finnis. Sapere Aude, v. 6, n. 11, p. 299-319. 2o Sem. 2015.

OLIVEIRA, Elton Somensi de. Bem comum, razão prática e direito: a fundamentação do conceito de bem comum na obra de John M. Finnis. 2002. Dissertação (Mestrado) - Universidade Federal do Rio Grande do Sul, Programa de Pós-Graduação em Direito, Porto Alegre, 2002.

SCANDROGLIO, Tommaso. La teoría neoclassica sulla legge naturale di Germain Grisez e John Finnis. Torino: G. Giappichelli Editore, 2012.

VALLEJO, Iván Garzón. "Bien común, pluralismo y derechos". In: ETCHEVERRY, Juan B. (ed.). Ley, moral y razón. Estudios sobre el pensamiento de John M. Finnis a propósito de la segunda edición de Ley natural y derechos naturales. México: Universidad Nacional Autónoma de México, 2013. p. 141-160.

WESTERMAN, Pauline C. The Disintegration of Natural Law Theory: Aquinas to Finnis. Leiden; New York; Köln: Brill, 1998. 